\title{
Effect of Ethanol in Paclitaxel Injections on the Ethanol Concentration in Exhaled Breath
}

\author{
Tohru Aomori, ${ }^{1,2,3}$ Hironori Makino, ${ }^{2}$ Masayuki Sekizuka, ${ }^{4}$ Tadahiro Hashita, ${ }^{2}$ Takuya Araki, ${ }^{2,3}$ \\ Keiko Iizuka, ${ }^{2}$ Tomonori Nakamura ${ }^{2,3}$ and Koujirou Yamamoto ${ }^{2,3}$ \\ 1 Center for Medical Education, Gunma University Graduate School of Medicine, Maebashi, Japan \\ 2 Department of Pharmacy, Gunma University Hospital, Maebashi, Japan \\ 3 Department of Clinical Pharmacology, Gunma University Graduate School of Medicine, Maebashi, Japan \\ 4 Faculty of Pharmacy, Takasaki University of Health and Welfare, Takasaki, Japan
}

\section{Abstract}

Background: Ethanol is included in certain injectable preparations of anticancer drugs to increase their solubility. Since the volume of ethanol in these preparations is approximately half of the total injection volume, the potential inhibitory effects of ethanol on the central nervous system cannot be disregarded, especially considering that patients may drive immediately after administration of the medication. Therefore, the concentration of ethanol was examined in exhaled breath after administration of paclitaxel, an anticancer medication containing ethanol.

Methods: The ethanol concentration in exhaled breath immediately after an intravenous infusion of paclitaxel was measured in 30 patients, using a balloon-type gas detector tube. Correlations between the concentration of ethanol in exhaled breath and the total amount of ethanol administered or the intravenous infusion speed were calculated.

Results: The mean ethanol concentration in exhaled breath was $0.028 \pm$ $0.015 \mathrm{mg} / \mathrm{L}$. The correlation between the ethanol concentration in exhaled breath and the total dose of ethanol was weak $\left(R^{2}=0.25 ; p=0.055\right)$, while the intravenous infusion speed showed a stronger positive correlation with the concentration of ethanol in the breath $\left(\mathrm{R}^{2}=0.49 ; \mathrm{p}=0.11\right)$. The maximum concentration of ethanol measured in exhaled breath $(0.06 \mathrm{mg} / \mathrm{L})$ was equivalent to $40 \%$ of the threshold for drunk driving, as specified in the Road Traffic Act in Japan.

Conclusion: In this study, no patient had a breath ethanol concentration exceeding the legal threshold for drunk driving. However, it is still advisable for patients to avoid driving after receiving paclitaxel injections. When driving cannot be avoided, patients should wait for a sufficient time after receiving the injection before driving. 


\section{Background}

Paclitaxel is an antineoplastic drug isolated from a bark extract of Taxus brevifolia (Taxaceae). ${ }^{[1]}$ The governments of the US and Canada approved paclitaxel for sale in 1992, and a parenteral solution of paclitaxel subsequently became commercially available in Japan in 1997. Paclitaxel induces formation of excess disordered microtubules by promoting microtubule polymerization and stability. Since paclitaxel inhibits depolymerization of microtubules, ${ }^{[2,3]}$ cell division is inhibited. Thus, paclitaxel has antitumor activity. Paclitaxel is used clinically in the treatment of ovarian, breast, endometrial, stomach, and non-small cell lung cancers in Japan. The main adverse drug reactions to paclitaxel include gastrointestinal symptoms, peripheral neuropathy, arthralgia, muscular pain, nausea and vomiting, epilation, and pyrexia.

Paclitaxel tends to be soluble in $N, N$-dimethylacetamide, acetonitrile, methanol, and ethanol but is relatively insoluble in water. Because $50 \%$ ethanol is used as the solvent for clinical paclitaxel injections, ${ }^{[4]}$ we hypothesized that impairment of specific central nervous system (CNS) functions by ethanol or its cleavage product, acetaldehyde, as well as adverse reactions related to intoxication, may occur following treatment with this preparation. Thus, the possibility of adverse reactions following intake of ethanol accompanying paclitaxel administration should not be overlooked.

Since many hospitals in Japan are located in rural areas and are not conveniently accessible by public transportation, most patients drive to the hospital. Thus, it is important to consider the possible CNS depressant actions of ethanol contained in injectable drug formulations, in order to reduce the risk of serious car accidents. Furthermore, in the Road Traffic Act in Japan, the breath ethanol concentration that constitutes drunk driving is $0.15 \mathrm{mg} / \mathrm{L}{ }^{[5]}$ This threshold is lower than those in the UK, USA, and Canada $(0.40 \mathrm{mg} / \mathrm{L})$, and those in Australia, Germany, and France $(0.25 \mathrm{mg} / \mathrm{L})$. It is important to ensure that patients who receive paclitaxel injections containing ethanol do not have breath ethanol concentrations exceeding the legal threshold. Although research on plasma ethanol concentrations following paclitaxel administration has been published previously, ${ }^{[6]}$ only a few reports have evaluated the correlation between ethanol intake during chemotherapy and the ethanol concentration in exhaled breath.

Here, we investigated the concentration of ethanol in exhaled breath after chemotherapy with an intravenous paclitaxel infusion.

\section{Methods}

\section{Patients}

Thirty Japanese outpatients (mean age $55 \pm 8.6$ years [range 35-74]; 2 male and 28 female) who received treatment with paclitaxel $(80-330 \mathrm{mg} /$ day $)$ for breast, ovarian, or gastric cancer were eligible subjects for this research. This clinical study was approved by the Institutional Review Board for Clinical Trials at Gunma University Hospital (Maebashi, Japan). Written consent was obtained from all patients after they were informed of the study procedure.

\section{Analysis of Ethanol Concentrations in Exhaled Breath}

The volume of ethanol administered and the infusion rate of ethanol were calculated from the volume of the paclitaxel infusion and the administration time. Immediately after administration of the intravenous infusion to a subject, a balloon-type gas detector tube (Kitagawa Gas Detector Tube System; Komyo Rikagaku Kogyo KK, Kanagawa, Japan) was used to measure the concentration of ethanol in exhaled breath. The levels of aspartic acid aminotransferase (AST) and alanine aminotransferase (ALT) were noted from the medical records, and the alcohol drinking history was taken from each patient.

\section{Statistics}

Correlations between the total amount of ethanol administered and the ethanol concentration in exhaled breath, and between the intravenous infusion speed and the ethanol concentration in exhaled breath, were calculated using Pearson's correlation coefficient. Regression analysis was applied to each combination. 


\section{Results}

\section{Patient Characteristics, Treatment, and Breath Ethanol Concentrations}

The patient characteristics, the amount of paclitaxel administered, the speed of the intravenous infusion, and the concentration of ethanol in exhaled breath are summarized in table I.
The average ethanol concentration in exhaled breath immediately after the intravenous infusion of paclitaxel was $0.028 \pm 0.015 \mathrm{mg} / \mathrm{L}$ (range $0.00-0.06$ ).

Hepatic function in all patients was assessed to be within the normal range, as indicated by AST and ALT values of $12-33 \mathrm{U} / \mathrm{L}$ and $12-62 \mathrm{U} / \mathrm{L}$, respectively.

Table I. Ethanol concentrations in exhaled breath of individual patients

\begin{tabular}{|c|c|c|c|c|c|c|c|c|}
\hline Patient no. & Age (y) & Sex & $\begin{array}{l}\text { Primary } \\
\text { disease } \\
\text { (type of } \\
\text { cancer) }\end{array}$ & $\begin{array}{l}\text { Paclitaxel } \\
\text { dose (mg) }\end{array}$ & $\begin{array}{l}\text { Total amount } \\
\text { of ethanol } \\
\text { administered } \\
(\mathrm{mL})\end{array}$ & $\begin{array}{l}\text { Duration } \\
\text { of infusion } \\
\text { (min) }\end{array}$ & $\begin{array}{l}\text { Infusion } \\
\text { speed of } \\
\text { ethanol } \\
(\mathrm{mL} / \mathrm{h})\end{array}$ & $\begin{array}{l}\text { Ethanol } \\
\text { concentration } \\
\text { in exhaled } \\
\text { breath }(\mathrm{mg} / \mathrm{L})\end{array}$ \\
\hline 1 & 66 & Female & Breast & 330 & 27.5 & 210 & 7.9 & 0.04 \\
\hline 2 & 61 & Female & Ovarian & 300 & 25.0 & 180 & 8.3 & 0.05 \\
\hline 3 & 50 & Female & Breast & 280 & 23.3 & 135 & 10.4 & 0.05 \\
\hline 4 & 35 & Female & Ovarian & 270 & 22.5 & 180 & 7.5 & 0.03 \\
\hline 5 & 58 & Female & Ovarian & 270 & 22.5 & 180 & 7.5 & 0.01 \\
\hline 6 & 56 & Female & Breast & 250 & 20.8 & 153 & 8.2 & 0.06 \\
\hline 7 & 52 & Female & Ovarian & 240 & 20.0 & 180 & 6.7 & 0.05 \\
\hline 8 & 49 & Female & Ovarian & 240 & 20.0 & 180 & 6.7 & 0.04 \\
\hline 9 & 56 & Female & Ovarian & 180 & 15.0 & 180 & 5.0 & 0.01 \\
\hline 10 & 55 & Female & Breast & 145 & 12.1 & 74 & 9.8 & 0.05 \\
\hline 11 & 54 & Female & Breast & 130 & 10.8 & 80 & 8.1 & 0.02 \\
\hline 12 & 68 & Female & Gastric & 120 & 10.0 & 108 & 5.6 & 0.03 \\
\hline 13 & 45 & Female & Breast & 120 & 10.0 & 70 & 8.6 & 0.04 \\
\hline 14 & 60 & Female & Breast & 120 & 10.0 & 99 & 6.1 & 0.03 \\
\hline 15 & 60 & Female & Breast & 120 & 10.0 & 95 & 6.3 & 0.03 \\
\hline 16 & 53 & Male & Gastric & 120 & 10.0 & 127 & 4.7 & 0.02 \\
\hline 17 & 51 & Female & Breast & 110 & 9.2 & 99 & 5.6 & 0.03 \\
\hline 18 & 52 & Female & Breast & 110 & 9.2 & 65 & 8.5 & 0.04 \\
\hline 19 & 40 & Female & Breast & 110 & 9.2 & 90 & 6.1 & 0.02 \\
\hline 20 & 53 & Female & Breast & 110 & 9.2 & 85 & 6.5 & ND \\
\hline 21 & 52 & Female & Gastric & 108 & 9.0 & 85 & 6.4 & 0.04 \\
\hline 22 & 58 & Female & Breast & 105 & 8.8 & 81 & 6.5 & 0.03 \\
\hline 23 & 58 & Female & Breast & 105 & 8.8 & 130 & 4.0 & 0.01 \\
\hline 24 & 39 & Female & Breast & 103 & 8.6 & 91 & 5.7 & 0.01 \\
\hline 25 & 74 & Female & Breast & 100 & 8.3 & 75 & 6.7 & 0.03 \\
\hline 26 & 66 & Female & Breast & 100 & 8.3 & 78 & 6.4 & 0.03 \\
\hline 27 & 49 & Female & Breast & 98 & 8.2 & 88 & 5.6 & 0.03 \\
\hline 28 & 61 & Female & Ovarian & 90 & 7.5 & 185 & 2.4 & 0.01 \\
\hline 29 & 64 & Female & Breast & 86 & 7.2 & 90 & 4.8 & 0.01 \\
\hline 30 & 55 & Male & Gastric & 80 & 6.7 & 100 & 4.0 & ND \\
\hline Average $\pm S D$ & $55 \pm 8.6$ & & & $155 \pm 76$ & $12.9 \pm 6.3$ & $119 \pm 45$ & $6.5 \pm 1.7$ & $0.03 \pm 0.02$ \\
\hline
\end{tabular}




\section{Relationship between Ethanol Concentrations in Exhaled Breath and the Total Volume or Infusion Speed of Ethanol}

The correlation coefficient between the total amount of ethanol administered via the intravenous infusion and the ethanol concentration in exhaled breath was weak $\left(\mathrm{R}^{2}=0.25 ; \mathrm{p}=0.055\right)$ [figure 1a]. In contrast, the intravenous infusion speed had a relatively stronger positive correlation with the concentration of exhaled ethanol $\left(\mathrm{R}^{2}=0.49 ; \mathrm{p}=0.11\right)$ [figure $1 \mathrm{~b}$ ].

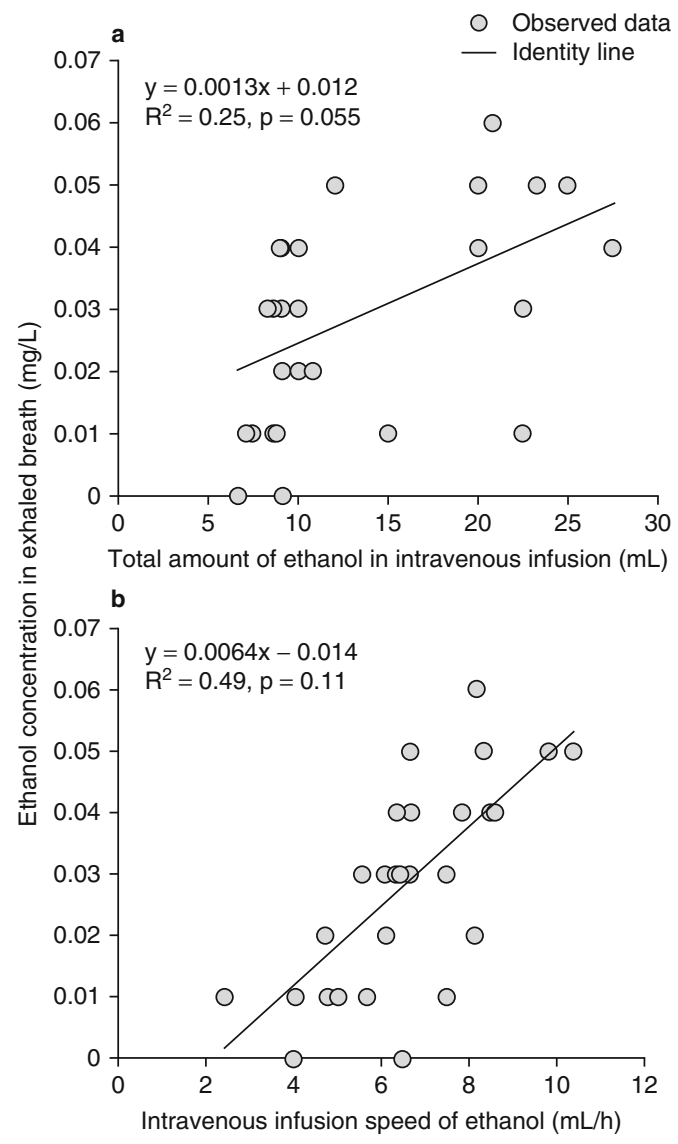

Fig. 1. Relationship between the ethanol concentration in exhaled breath and (a) the total amount of ethanol administered via the in travenous paclitaxel infusion; and (b) the speed of the paclitaxel infusion. The data-point markers represent observed data. The oblique black data lines represent the fitted curves.

\section{Discussion}

More than $90 \%$ of ethanol is metabolized by alcohol dehydrogenase (ADH) and aldehyde dehydrogenase 2 (ALDH2) in the liver. ${ }^{[7]}$ It has been reported that people with low ALDH2 activity show hereditary sensitivity to the effects of alcohol, and approximately $50 \%$ of Japanese people are poor alcohol metabolizers. ${ }^{[8]}$ Thus, the percentage of Japanese people who experience facial flush and heart palpitations in association with elevated blood aldehyde concentrations after drinking alcohol is larger than that of Europeans and Americans. Inter-individual differences in alcohol metabolism are also larger in the Japanese population. Therefore, there is a greater risk of intoxication leading to a car accident in people who have poor ethanol metabolism, because the blood ethanol concentration remains high even after consumption of a relatively small amount of alcohol.

Ethanol is eliminated primarily by a saturable (Michaelis-Menten) process. ${ }^{[8]}$ Hence, the halflife of ethanol changes according to the dose or the rate of administration. Paclitaxel injections contain $50 \%(\mathrm{v} / \mathrm{v})$ ethanol; thus, if $300 \mathrm{mg}$ of paclitaxel is injected, $25 \mathrm{~mL}$ ethanol is also administered. This amount is equivalent to $500 \mathrm{~mL}$ of beer or $60 \mathrm{~mL}$ of whisky. Furthermore, because the first-pass effect does not apply to intravenous infusions, the effects of ethanol will be greater than with oral administration. In this study, an ethanol concentration in exhaled breath that exceeded the threshold for drunk driving, as specified in the Road Traffic Act, was not detected in any patient, but there was one case that reached more than $40 \%$ of the threshold. Moreover, a previous report described several cases that exceeded the threshold defined by the law. ${ }^{[9]}$

The relationship between the ethanol concentration in breath and that in blood has been investigated, and a method of deducing the blood concentration from the concentration in breath has been established. Moreover, when considering the CNS effects, the ethanol concentration in breath (which reflects the arterial blood ethanol concentration) is considered to be a more suitable indicator than the venous blood ethanol concen- 
tration. The ratio of venous blood ethanol concentrations to exhaled breath ethanol concentrations is approximately $2000: 1 .^{[7]}$

The average blood ethanol concentration estimated from our findings was $0.06 \pm 0.03 \mathrm{mg} / \mathrm{mL}$. Webster et al. reported that the average plasma ethanol concentration after administration of paclitaxel in Caucasian patients was $0.07 \pm 0.10 \mathrm{mg} / \mathrm{mL}$. ${ }^{[6]}$ When the average doses of paclitaxel in both studies (155 \pm 76 and $293 \pm 35 \mathrm{mg}$, respectively) are taken into consideration, the estimated blood ethanol concentrations may have been a little higher in our study. The difference in the body size between Japanese and Caucasian subjects may have affected this.

Because ethanol has a fast elimination rate, its concentrations steady state rapidly, and this is why the plasma ethanol concentration at the end of administration depends on the infusion speed. Thus, the ethanol concentration in exhaled breath after administration of paclitaxel is considered to be affected by the infusion speed but not by the total amount of ethanol administered. There were several subjects who complained of facial flush or light-headedness after the end of the intravenous infusion, which may have been a response to the ethanol metabolite, acetaldehyde. ${ }^{[10]}$ In these cases, markers other than the breath ethanol concentration should be considered, in order to assess the degree of intoxication. In general, patients with high sensitivity to ethanol tend to present with symptoms of alcohol impairment and also have impaired decision-making ability.

The gender bias of the patients should be mentioned as a limitation of this study. Because most patients in the study were outpatients with breast cancer or ovarian cancer, the majority of the patients were female. It has previously been shown that when the same dose of ethanol is administered to male and female subjects, higher blood concentrations are reached in females than in males, ${ }^{[1]}$ and this may have affected our results.

\section{Conclusion}

We have shown that the ethanol concentration in exhaled breath after administration of pacli- taxel is affected by the infusion speed rather than by the total amount of ethanol administered. However, it is difficult to predict from this information which patients will show a high breath ethanol concentration. Hence, all outpatients receiving paclitaxel should avoid driving from hospital when possible and, if driving is unavoidable, they should drive only after taking a sufficient break. The possible effects of the ethanol additive should be considered carefully when administering drugs, such as paclitaxel, with a high volume of ethanol additive.

\section{Acknowledgments}

The authors thank Mr. Ryo Morishima, Ms. Harumi Kogure, and Ms. Kyoko Homma for their technical assistance, and Ms. Aiko Matsumoto for her secretarial assistance.

No sources of funding were used to conduct this study or prepare this manuscript. The authors have no conflicts of interest that are directly relevant to the content of this manuscript.

\section{References}

1. Wani MC, Taylor HL, Wall ME, et al. Plant antitumor agents: VI. The isolation and structure of taxol, a novel antileukemic and antitumor agent from Taxus breviforia. J Am Chem Soc 1971 May 5; 93 (9): 2325-7

2. Schiff PB, Horwitz SB. Taxol stabilizes microtubules in mouse fibroblast cells. Proc Natl Acad Sci U S A 1980 Mar; 77 (3): 1561-5

3. Schiff PB, Fant J, Horwitz SB. Promotion of microtubule assembly in vitro by taxol. Nature 1979 Feb; 277 (5698): 665-7

4. Bristol-Myers Squibb Company. Taxol ${ }^{\circledR}$ (paclitaxel) injection: package insert. Princeton (NJ): Bristol-Myers Squibb Company, 2011 Apr [online]. Available from URL: http:// packageinserts.bms.com/pi/pi_taxol.pdf [Accessed 2012 Aug 20]

5. Ministry of Land, Infrastructure, Transport and Tourism of Japan. Road Traffic Act of Japan. Tokyo: Ministry of Land, Infrastructure, Transport and Tourism of Japan, 2009

6. Webster LK, Crinis NA, Morton CG, et al. Plasma alcohol concentrations in patients following paclitaxel infusion. Cancer Chemother Pharmacol 1996; 37 (5): 499-501

7. Fleming M, Mihic SJ, Harris RA. Ethanol. In: Hardman JG, Limbird LE, editors. Goodman \& Gilman's: the pharmacological basis of therapeutics. 10th ed. New York: McGraw-Hill, 2011: 429-45

8. Harada S, Misawa S, Agarwal DP, et al. Liver alcohol dehydrogenase and aldehyde dehydrogenase in the Japanese: isozyme variation and its possible role 
in alcohol intoxication. Am J Hum Genet 1980 Jan; 32 (1): $8-15$

9. Komagata H, Yoneda S, Sakai H, et al. Breath alcohol concentrations in Japanese outpatients following paclitaxel and docetaxel infusion. Int J Clin Pharmacol Res 2005; 25 (4): $195-202$

10. Mizoi Y. Individual difference in sensitivity to alcohol. Nihon Rinsho 1997; 55 Suppl.: 106-10
11. Ramchandani VA, Bosron WF, Li TK. Research advances in ethanol metabolism. Pathol Biol (Paris) 2001; 49 (9): 676-82

Correspondence: Dr. Koujirou Yamamoto, Department of Clinical Pharmacology, Gunma University Graduate School of Medicine, 3-39-22 Showa-machi, Maebashi 371-8511, Japan. E-mail: koujirou@gunma-u.ac.jp 